ВІСНИК

ОДЕСЬКОГО НАЦІОНАЛЬНОГО

МОРСЬКОГО УНІВЕРСИТЕТУ
HERALD

OF THE ODESSA NATIONAL

MARITIME UNIVERSITY № 1 (64), 2021

УДК 621.43.044.7

DOI 10.47049/2226-1893-2021-1-99-111

\title{
ПЕРСПЕКТИВА ИСПОЛЬЗОВАНИЯ ЛИТИЕВО-ИОННЫХ АККУМУЛЯТОРНЫХ БАТАРЕЙ
}

\section{Л.В. Кошарская}

к.т.н., доцент кафедры «Техническое обслуживание и ремонт судов»

\section{Ю.А. Никифоров}

к.т.н., доцент,

заведующий кафедрой «Техническое обслуживание и ремонт судов»

$$
\text { С.Ю. Володин }
$$

ст.преподаватель кафедры «Техническое обслуживание и ремонт судов»

\section{Одесский национальный морской университет}

Аннотация. В статье проанализировано влияние выбросов токсичных отходов и необходимость применения альтернативных энергетических источников.

Описаны недостатки существующих источников, а также указаны преимущества применения аккумуляторных батарей.

Литиево-ионные батареи, по сравнению с традиционными энергетическими установками, являются экологичными. В настоящее время это очень актуально.

ионная батарея.

Ключевые слова: аккумуляторная батарея, литий, литиево-

УДК 621.43.044.7

DOI 10.47049/2226-1893-2021-1-99-111

\section{ПЕРСПЕКТИВА ВИКОРИСТАННЯ ЛІТІЕВО-ІОННИХ АКУМУЛЯТОРНИХ БАТАРЕЙ}

\section{Л.В. Кошарська}

к.т.н., доцент кафедри «Технічне обслуговування і ремонт суден»

\section{Ю.О. Никифоров}

$$
\text { к.т.н., доцент, }
$$

заведувач кафедри «Технічне обслуговування і ремонт суден»

$$
\text { С.Ю. Володін }
$$

ст. викладач кафедри «Технічне обслуговування і ремонт суден»

Одеський національний морський університет

Анотація. У статті проаналізований вплив викидів токсичного сміття і необхідність застосування альтернативних енергетичних джерел.

( Кошарская Л.В., Никифоров Ю.А., Володин С.Ю., 2021 
Описані недоліки існуючих джерел, а також вказані переваги застосування акумуляторних батарей.

Літієво-іонні батареї у порівнянні з традиційними енергетичними установками є більш екологічними. У теперішній час ие дуже актуально.

Ключові слова: акумуляторна батарея, літій, літієво-іонна батарея.

UDC 621.43.044.7

DOI 10.47049/2226-1893-2021-1-99-111

\title{
THE PERSPECTIVE OF USING LITHIUM-ION BATTERTIES
}

\author{
L.V. Kosharska \\ Candidate of Technical Sciences, \\ Associate Professor of the Department «Technical service and repair of ships» \\ Yu.O. Nikiforov \\ Ph.D., associate professor, \\ head of the department «Technical service and repair of ships» \\ S.Yu. Volodin \\ Department of «Technical service and repair of ships»

\section{Odessa National Maritime University}

Abstract. The article analyzes the impact of emissions of toxic waste and the need to use alternative energy sources.

The disadvantages of existing sources are described, and advantages of using rechargeable batteries.

Lithium-ion batteries are environmentally friendly compared to traditional power plants. Currently this is very relevant.

Keywords: Storage battery, lithium, Lithium-ion battery.

Введение. Ничто не влияет на состояние природы так, как деятельность человека, никакие стихийные бедствия не оказывают более серьезного и долговременного эффекта на окружающую среду. Выбросы токсичных отходов отравляют воду, воздух и почву и приводят к гибели целых экосистем. Применение вредных технологий сказывается на всём комплексе элементов нашей земной атмосферы.

Охрана окружающей среды не была приоритетом вплоть до середины XX века, хотя к тому моменту антропогенная деятельность уже давно оказывала самое негативное влияние на природу.

Лишь на 27 сессии Генеральной ассамблеи ООН был впервые всерьез поднят данный вопрос. Тогда же в системе $\mathrm{OOH}$ была создана новая организация - Программа ООН по окружающей среде (ЮНЕП). 
Постановка проблемы. Перед защитниками природы в настоящее время стоит немало проблем. Антропогенная деятельность разнообразна, и так же разнообразно ее влияние на нашу среду обитания. Основные цели, на которых сегодня сосредоточено внимание экологов:

- ограничение выбросов токсичных отходов, отравляющих атмосферу, воду и почву;

- создание заповедников для защиты уникальных природных комплексов и экосистем;

- ограничение охоты и рыболовства для сохранения исчезающих видов, внедрение новых методов промысла, наносящих минимальный вред природе;

- ограничение выброса мусора и поиск путей его переработки.

Для защиты природы было разработано множество международных соглашений. Пожалуй, самым известным можно назвать Киотский протокол, который обязал развитые страны строго контролировать объем выбросов углекислого газа для предотвращения появления парникового эффекта, влияющего на климат во всем мире.

Кроме того, была принята Конвенция ООН по морскому праву, направленная на защиту морей.

Это - Монреальский протокол, который ограничивает производство и использование веществ, разрушающих озоновый слой атмосферы, a также Конвенция о биологическом разнообразии, которая направлена на охрану и рациональное использование ресурсов живой природы, и еще десятки важных документов.

Всемирный фонд дикой природы (международная общественная организация, работающая в сферах, касающихся сохранения, исследования и восстановления окружающей среды) участвует в программах защиты морской среды обитания, расширении лесных зон, сохранения существующих климатических условий и другие программы в масштабе планеты.

Независимая международная экологическая организация, такая как Гринпис, прославилась заметными общественными акциями. Сейчас деятельность Гринпис направлена в основном на защиту биологического разнообразия, сокращение выброса газов в атмосферу и производства токсичных отходов, а также против развития и использования ядерных технологий. Немало сделано и для внедрения экологичных методов сбора, сортировки и переработки мусора.

Программа ООН (ЮНЕП) - главный орган ООН по защите окружающей среды и одна из самых масштабных природоохранных организаций мира. Ее деятельность в основном направлена на Мониторинг экологии, разработку законов и правил, а также просветительскую деятельность. В частности, именно благодаря ЮНЕП были приняты нормы и правила перевозки опасных и токсичных веществ. 
ЮНЕП является одной из самых масштабных организаций поддерживающих применение аккумуляторных батарей, в том числе (одна из первых) рекомендовала обратить внимание на применение литиево-ионных батарей.

Ещё одна Конвенция Защиты окружающей среды - это Международная конвенция по предотвращению загрязнения с судов (англ. International Convention for the Prevention of Pollution from Ships, MARPOL 73/78). Она предусматривает комплекс мер по предотвращению эксплуатационного и трансграничного загрязнения моря судами с нефтью, жидкими веществами в больших количествах, вредными веществами в упаковке, сточными водами и балластными водами.

Конвенция по предотвращению загрязнения с судов (МАРПОЛ 73/78) состоит из собственно Конвенции и Протоколов к ней, где закрепляются общие положения об обязательствах государств-участников по предотвращению загрязнения моря с судов, и шести Приложений к ней, излагающих Правила относительно загрязнения моря конкретными загрязняющими веществами: нефтью, вредными химическими веществами, перевозимыми наливом, веществами, перевозимыми в упакованной форме, сточными водами, мусором и загрязнения воздушной среды с судов.

МАРПОЛ-73/78 является главным международным документом, в котором предусмотрены меры по сокращению и предотвращению загрязнения морской среды вредными веществами, перевозимыми на судах или образующимися в процессе их эксплуатации.

Цель исследований. Учитывая ограничения, налагаемые Конвенцией МАРПОЛ на уровень выбросов в окружающую среду, в данной работе рассматривается эффективность применения аккумуляторных батарей (АБ), как главного источника получения энергии на транспортных объектах.

Исходя из современных требований по защите окружающей среды и ряда других факторов, рассматриваются вопросы применения альтернативных источников энергии. К одному из таких относится энергия аккумуляторных батарей. Особое внимание привлекают литиево-ионные аккумуляторные батареи.

Литиево-ионная аккумуляторная батарея - это тип электрического аккумулятора, который широко распространён в современной технике, промышленности, автотехнике, транспорте, накопителях энергии в электрических системах, космонавтике, морском транспорте, Военно-Морском флоте (в частности - на подводных лодках).

Литиево-ионные аккумуляторные батареи уже достаточно широко применяются на подводных лодках в тех приборах, устройствах и механизмах, где наивыгоднейшим образом можно применить их свойства. 
Основные задачи для АБ на современных ДЭПЛ и АРЛ:

- обеспечение движения в подводном положении (гребных электродвигателей);

- обеспечение работы всех электрических приборов и устройств в подводном положении; генератора;

- обеспечение работы аварийного источника питания дизельвооружения.

- обеспечение режима готовности специальных устройств и

Литиево-ионную АБ можно размещать комфортно в любых отсеках и даже в неудобных объемах (внутри прочного корпуса и снаружи).

Особенности эксплуатации литиево-ионных батарей:

- литиево-ионные батареи выдерживают хранение в разряженном состоянии в течение нескольких лет, в тоже время свинцово-кислотная батарея (при стандартных параметрах в месте хранения - одинаковых с литиево-ионной батареей) выдерживает срок 12-16 месяцев.

- конструкция литиево-ионных аккумуляторов и батарей позволяет выдерживать большие механические (взрывные) нагрузки, а свинцово-кислотные батареи подвержены расплёскиванию электролита.

- стоимость одного (Вт·ч) для литиево-ионного аккумулятора в 15-25 раз ниже, чем свинцово-кислотного в расчете на один цикл.

Особое преимущество литиево-ионной АБ состоит в возможности полного отказа от такого конструктивного элемента, как аккумуляторная яма с обслуживающими ее многочисленными системами.

В 2020 году в состав Морских сил самообороны Японии принята первая в мире боевая подводная лодка с литиево-ионными аккумуляторами.

Оснащение литиево-ионными аккумуляторными батареями позволило отказаться от применения не только традиционных свинцово-кислотных аккумуляторных батарей, но и воздухонезависимых двигателей: это тепловая машина, в которой рабочее тело в виде газа или жидкости движется в замкнутом объёме, разновидность двигателя внешнего сгорания. Основан на периодическом нагреве и охлаждении рабочего тела с извлечением энергии из возникающего при этом изменения давления. Может работать не только от сжигания топлива, но и от любого источника тепла.

Решение об использовании литиево-ионных NCA-аккумуляторов на подводных лодках типа «Сорю» было принято по нескольким причинам:

- такие аккумуляторы имеют существенно бо́льшую емкость, чем свинцово-кислотные, при этом на малых скоростях дальность подводного хода подлодки на литиево-ионных аккумуляторах сопоставима с дальностью хода на свинцово-кислотных аккумуляторах и двигателе Стирлинга. 
- на больших скоростях дальность хода корабля с литиевоионными аккумуляторными батареями заметно превышает такой показатель при использовании свинцово-кислотных аккумуляторов.

- литиево-ионные аккумуляторы можно перезаряжать с использованием бо́льших токов, чем при зарядке свинцово-кислотных элементов питания: это означает, что на полную зарядку литиево-ионных батарей необходимо существенно меньше времени.

\section{батареи:}

Основные преимущества, которые имеют литиево-ионные

- более короткое время подзарядки по причине большей силы тока заряда, по сравнению со свинцово-кислотными батареями;

- больший срок службы;

- не требуют технического обслуживания;

- электрические системы с их применением проще в управлении и в построении литиево-ионных АБ. требуют:

Литиево-ионные батареи при применении на подводных лодках

- более мощных дизель-генераторов для подзарядки;

- некоторых изменений в электрических цепях: в первую очередь применения автоматических предохранителей.

Исходя из вышесказанного, рассмотрим основные направления применения литиево-ионных АБ в гражданском судостроении и использовании в транспортном флоте.

В настоящее время около $90 \%$ товаров в мире перевозится морским транспортом, и хотя морские грузоперевозки можно сделать более щадящими для окружающей среды, чем авиаперевозки, грузовые суда по-прежнему работают на ископаемом топливе. На сегодняшний день выбросы от сжигания дешевого ископаемого топлива в судоходстве составляют примерно $2 \%$ всех мировых выбросов $\mathrm{CO}_{2}$ в сфере энергетики.

Современные энергетические установки, использующие различные виды топлива, далеки от требований экологических нормативов.

Используемые в настоящее время двигатели имеют: на);

- достаточно большой вес (по отношению к весу корпуса суд-

- большие габариты (исходя из размеров не грузовых площадей и объёмов);

- много обеспечивающих устройств, механизмов, трубопроводов, нуждающихся в обеспечении электрической энергией;

- все вспомогательные устройства, механизмы, трубопроводы и т.п. нуждаются в обслуживании и ремонте.

Применяемое на судах топливо является ископаемым. Расходы топлива постоянно из года в год растут, а восстановление природных запасов (нефти и газа) не происходит. 
Потребность топлива в различных его формах увеличивается, стоимость добычи, транспортировки, переработки, хранения и доставки к потребителю тоже растёт.

Ведущие инженеры и учёные выполняют исследовательские работы и проводят эксперименты с другими носителями энергии: квантовые, фотонные и другие типы двигателей.

Замена дизельной установки (главного двигателя) на гребной электродвигатель даёт следующие выгоды:

- освобождается большая площадь МО от:

1) непосредственно самого дизельного двигателя;

2) вспомогательных устройств и механизмов (с их фундаментами), обеспечивающих его работу;

3) большого количества трубопроводов и кабельных трас, обеспечивающих его работу;

4) всевозможных цистерн, начиная от топливных и заканчивая расходными;

- улучшаются удобства обслуживания оставшихся механизмов и устройств. Взрывопожароопасность уменьшается в несколько раз; габаритах;

- увеличивается грузоподъёмность судна при меньших общих

- появляется реальная возможность создания автоматизированного судна с низким коэффициентом аварийности и управление судном посредством космической связи становится реальностью.

Заинтересованные организации в результате сравнительного анализа различных видов аккумуляторных батарей установили, что литиево-ионные АБ обладают преимущественными характеристиками:

- высокая энергетическая ёмкость;

- низкий саморазряд;

- высокая токоотдача;

- большое число циклов - заряд-разряд;

- безопасность - отсутствие выделения водорода и хлора;

гии);

- малые размеры (по сравнению с другими источниками энер-

- простота технического обслуживания.

Принцип работы литиево-ионных аккумуляторов основан на реакциях окисления металлического лития, который входит в состав анода (положительный электрод). При разрядке металл окисляется и в форме катиона (положительно заряженный ион) движется к катоду (отрицательный электрод). При зарядке происходит обратный процесс. Литиевые аккумуляторы легче и безопаснее применявшихся ранее, у них низкая саморазрядка. Батареи такого типа можно регулярно подзаряжать.

Литиево-ионный аккумулятор - тип электрического аккумулятора, который широко распространён в современной бытовой электрон- 
ной технике, применяется в качестве источника энергии в электромобилях и накопителях энергии в энергетических системах. Кроме этого эти батареи уже опробированы и установлены на экспериментальных кораблях, подводных лодках и некоторых космических станциях.

Характеристики литиево-ионных аккумуляторов зависят от химического состава составляющих компонентов и варьируются в следующих пределах:

- напряжение единичного элемента:

- максимальное:

$\sim 4,2$ B;

- минимальное:

$\sim 2,5 \mathrm{~B}$

- удельная энергоёмкость:

- внутреннее сопротивление:

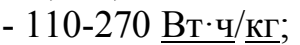

- 4-15 $\underline{\mathrm{MOM}}$;

- число циклов заряд-разряд до снижения ёмкости

- время быстрого заряда:

- до $80 \%$ : 600;

- саморазряд зависит от температуры хранения и степени заряда:

- при температуре $25^{\circ} \mathrm{C}$ и заряде $100 \%$

- ток нагрузки относительно ёмкости С, представленной в $\underline{\mathrm{A} \cdot \mathrm{q}}$

- постоянный:

- импульсный:

- оптимальный:

- диапазон рабочих температур:

$\sim 1$ час;

$\approx 1,6 \%$ в месяц;

- до $5 \mathrm{C}$;

- до $50 \mathrm{C}$;

- до $1 \mathrm{C}$;

- от $-20{ }^{\circ} \mathrm{C}$ до $+60{ }^{\circ} \mathrm{C}$

(оптимальная $+23^{\circ} \mathrm{C}$ );

Преимуществом литиево-ионных АБ является их высокая удельная энергия. Именно поэтому с каждым годом процесс применения данного рода АБ в технике (механизмы, транспорт: наземный, морской и космический) только расширяется.

В течение ближайших 4-х лет в рамках программы «Международное развитие судостроения на 2013-2030 годы» будет построено более 1300 гражданских судов и до 652 кораблей. Аналитики предполагают, что рынок судов и кораблей, использующих литиево-ионные аккумуляторы, составлял в 2020 г. более 0,7 млрд долл., то в 2021 г. может составить уже 1 млрд. долл.

В 2009 году Mitsui O.S.K. Lines (MOL) разработала основные параметры концептов судов, оснащенных накопительными литиево-ионными батареями, а в 2012 году приняла в эксплуатацию первый гибридный автомобилевоз с подобным накопителем энергии. А в январе 2018 года Asahi Tanker совместно с японской корпорацией Exeno-Yamamizu Corporation разработали проект первого в мире танкера с полностью электрическим двигателем, где главным источником энергии будет электричество от литиево-ионных батарей. 
Выпуском аккумуляторов GS Yuasa занимается с конца позапрошлого века. Специализированные батареи приносят компании лишь $5 \%$ дохода.

Литиево-ионные батареи данной марки снабжают электроэнергией МКС на высоте 400 км от поверхности Земли, накапливая заряд от солнечных панелей. Международная станция совершает за сутки 16 полных оборотов вокруг Земли, столько же циклов заряда и разряда приходится проделывать бортовым аккумуляторам. Литиево-ионные батареи, которые установлены на МКС, имеют при этом расчётный срок эксплуатации не менее десяти лет.

По словам представителей компании, предполагается разработка и развитие новых поколений литиево-ионных аккумуляторов. С их помощью компания рассчитывает начать освоение воздушного пространства:

- во-первых, ёмкие и лёгкие батареи потребуются летающим станциям беспроводной связи;

- во-вторых, со временем они найдут применение и в полноразмерных авиалайнерах.

Несмотря на достаточно внушительный ряд преимуществ применения литиево-ионных АБ, следует, конечно, остановиться на серьёзных проблемах их применения.

Литий - это легкий металл, но он обладает сильными отрицательными электрохимическими свойствами. Благодаря этому он характеризуется большой теоретической удельной электроэнергией.

Источники тока на базе лития дают большое разрядное напряжение и хорошую емкость.

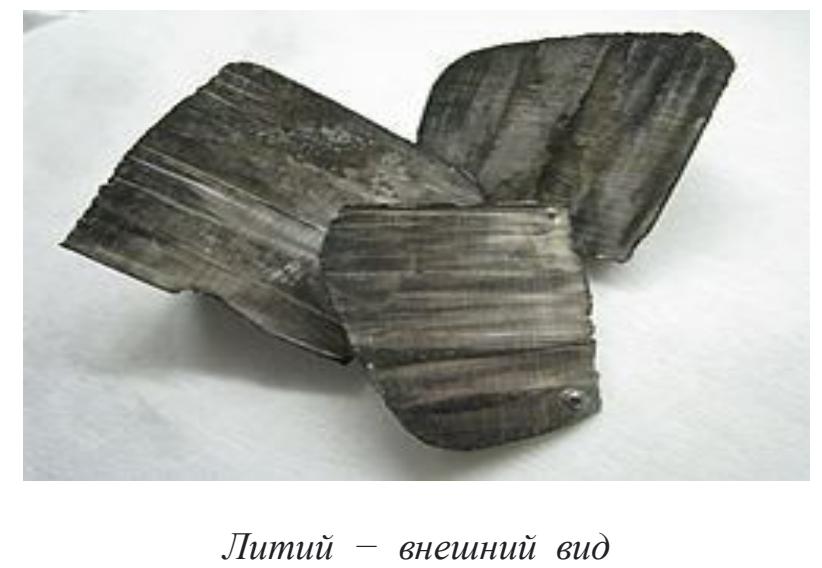

Именно благодаря вышеприведенным параметрам литиевоионных аккумуляторов с каждым годом увеличивается тенденция к 
росту применения данного рода АБ в технике (механизмы, транспорт: наземный, морской и космический).

Для создания высокой ёмкости литиево-ионные АБ соединяются параллельно или последовательно.

Таким образом АБ может достигать:

- напряжения до 500-700 В постоянного тока с ёмкостью около $400 \mathrm{~A} / \mathrm{ч}$;

- ёмкости до 2 000-3 000 А/ч с напряжением 48 или 98 В.

Основные недостатки применения литиево-ионых батарей:

- увеличивается нагрузка на системы автоматизации и контроля;

- становится более жесткий контроль за работой АБ (в связи c её герметичностью) для избежания проблемы образования металлического лития на внутренней поверхности электродов;

- необходимость герметизации аккумуляторных помещений;

- появятся дополнительные требования Классификационных обществ к надзору за работой литиево-ионных батарей;

- в надзоре примут участие и другие надзорные и страховые организации;

- максимальный ток заряда и разряда данных АКБ должен быть ограничен;

- должна контролироваться температура элементов аккумулятора.

Кроме достаточно существенных преимуществ литиево-ионных АБ, следует остановиться на серьёзных проблемах их практического применения.

На сегодняшний день объём литиево-ионных аккумуляторов достаточно мал для промышленной переработки. Это в основном потребительская электроника и (малое количество - пока они в большинстве своём новые) электромобилей. Информация о количестве используемых литиевых батарей на морском транспорте, космических аппаратах и ВМФ (в основном на ПЛ) отсутствует.

При современной переработке литиево-ионных аккумуляторов выделяются токсичные элементы и газы. Кроме того, материалы, из которых производятся аккумуляторы (такие, как литий и кобальт), находятся в природе в ограниченном количестве и не возобновляются. Их дополнительное производство (а не повторное использование) приводит к, соответственно, дополнительной нагрузке на экологию планеты, поскольку производственные процессы довольно энергоемкие.

Ориентировочные расчёты показывают, что к 2030 году на земле будет уже 140 млн. электрических машин. И они «произведут» более 11 млн. тонн отходов в форме использованных литиево-ионных батарей. Учитывая то, что современные запасы лития в мире оцениваются в величину более 53 млн. тонн, то количество отходов лития 
(далеко не полная информация) и его запасы становятся сопоставимыми.

В то же время здесь существует следующая технологическая проблема. Процесс переработки пока не позволяет выделять ценный литий, который остаётся в составе «побочного продукта». Для получения лития из этих остаточных сплавов требуется дальнейшее развитие технологий и соответствующие затраты.

В бельгийском Антверпене действует пилотный завод по переработке использованных аккумуляторов. Технология предполагает плавку батарей с выделением в процессе ценных металлов, таких как никель и кобальт.

По оценкам инвестиционных банков технология извлечения лития из старых аккумуляторов, не будет работать ещё как минимум десять лет. С теоретической точки зрения, это возможно уже сейчас, а вот экономика процесса пока неудовлетворительна.

Проблему усугубляет и то, что удельная стоимость переработки литиево-ионных аккумуляторов, которая сегодня приближается к 1 евро за килограмм, примерно в три раза выше, чем удельная стоимость получаемых на выходе материалов.

Другими словами, технологии переработки существуют, но пока не являются, так сказать, полноценными и экономически доступными.

По этой причине ищутся решения, позволяющие как можно дольше отсрочить «окончательную» переработку. Одним из них является повторное использование аккумуляторов в системах хранения энергии.

Что же касается перспектив глубокой переработки, то уже есть достаточно предложений на методы извлечения лития и других материалов. Например, предлагается использовать химические процессы для выделения ценных металлов из старых аккумуляторов.

В 2015 году мировой рынок переработки литиево-ионных аккумуляторов стоил всего около 1,7 млн. евро. Ожидается, что в 2030 г. его размер превысит 20 млрд. евро. Таким образом, ожидается рост рынка в более чем 10000 раз!!!

Проблемы в утилизации литиево-ионных аккумуляторов на современном этапе использования батарей:

- отсутствует выгодная утилизационная технология по переработке этих батарей (температура процесса превышает $\sim 200{ }^{\circ} \mathrm{C}$ );

- стоимость выделенных (восстановленных) элементов (литий и кобальт) превышает промышленную стоимость этих элементов;

- не решён вопрос с переработкой выделяющихся при утилизации токсичных газов и элементов.

Если учесть перспективность применения литиево-ионных батарей в:

- промышленности; 
- энергонакопительных системах;

- транспорте (в том числе и морском);

- космических аппаратах;

- оборонной промышленности и так далее,

то вырисовываются следующие проблемы, которые надо решать уже сегодня.

Это следующие направления:

- организация сбора отработавших аккумуляторных батарей;

- разведка новых приисков лития;

- разведка новых приисков элементов, используемых в создании литиево-ионных батарей;

- создание новых предприятий по добыче лития;

- создание новых предприятий по добыче материалов, используемых в создании литиево-ионных батарей;

- создание предприятий по изготовлению и сборке литиевоионных батарей;

- создание новых конструкторско-исследовательских организаций;

- отработка системы использования вторичных: лития и других элементов для создания литиево-ионных батарей;

- отработка системы по переработке корпусов отработанных или повреждённых литиево-ионных батарей;

- утилизация отходов от переработки литиево-ионных батарей.

\section{Выводы}

- На сегодняшний день проблема утилизации литиево-ионных аккумуляторов окончательно не решена.

- Проблема утилизации литиево-ионных батарей требует больших капитальных вложений на разработку системы и её внедрения в жизнь;

- При применении литиево-ионных батарей на судах морского флота потребуются дополнительные финансовые расходы на проведение утилизации отработавших свой срок батарей.

- Достаточно много компаний работает над проблемой переработки литиево-ионных батарей и исследуются вопросы от термической переработки до процессов в вакууме;

- Ведутся работы по созданию новых химических соединений на базе лития и других элементов, которые можно использовать в накопителях и держателях энергии.

- Существует большое количество преимуществ применения литиево-ионных аккумуляторных батарей на морском транспорте, но и имеется ещё достаточно не решённых вопросов, в частности связанных с утилизацией литиево-ионных батарей. 
ВІСНИК

ОДЕСЬКОГО НАЦІОНАЛЬНОГО

МОРСЬКОГО УНІВЕРСИТЕТУ

№ 1 (64), 2021
HERALD

OF THE ODESSA NATIONAL

MARITIME UNIVERSITY

№ 1 (64), 2021

- Решению данного вопроса и должны быть посвящены современные исследования - научно-технические и экспериментальные работы.

- Применение литиево-ионных аккумуляторных батарей позволяет изменить условия работы в машинном отделении в комфортную сторону.

\section{ЛІТЕРАТУРА}

1. Литиевые батареи: Состояние, проспекты и будущуее // Научный журнал энергетических источников. - № 10. - 2016. C.27-29.

2. Мельничук, О.В. Особенности заряда и разряда литиевых аккумуляторных батарей и современные технические средства управления этими процессами // Морское инженерное обозрение. - № 9. - 2016. - C.17-21.

3. Де Хаан. Практическое судостроение. Ч. 1. - Техническое издательство. - Голландия, 1997.

4. Петров А. Экологические дизели нового века // Судоходство. № 1-2, 2001. - C.32-33.

\section{REFERENCES}

1. Lithium batteries: Status, prospects and future: Journal of Power Sources. 10.2016. - P. 27-29.

2. Melnichuk, O.V. Special aspects for charging and discharging of Lithium batteries and modern technical means of control for such processes //Marine engineering review. - № 9. - 2016. - P. 17-21.

3. De Haan. Practical shipbuilding. Part I. The technical publishing company. Holland, 1997.

4. Petrov, A. Acological diziel engine // Shipping. - № 1-2, 2001. P. 32-33.

Стаття надійшла до редакиії 19.03.2021

Посилання на статтю: Кошарская Л.В., Никифоров Ю.А., Володин С.Ю. Перспектива использования литиево-ионных аккумуляторных батарей // Вісник Одеського національного морського університету: Зб. наук. праць, 2021. № 1 (64). C. 99-111. DOI 10.47049/2226-1893-2021-1-99-111.

Article received 19.03.2021

Reference a JournalArtic: Kosharska L.V., Nikiforov Yu.O.,Volodin S.Yu. The perspective of using lithium-ion batterties // Herald of the Odessa National Maritime University. 2021. 1(64), 99-111. DOI 10.47049/ 2226-1893-2021-1-99-111. 